\title{
A symmetrical turning during spermatophore transfer in the male smooth newt
}

\author{
A N D Y J. GREEN \\ Estación Biológica de Doñana, Consejo Superior de Investigaciones Cientificas \\ ( Received 3 J une 1996; initial acceptance 6 A ugust 1996; \\ final acceptance 180 ctober 1996; M S. number: 5262)
}

\begin{abstract}
A bstract. During mating, male smooth newts, Triturus vulgaris, showed a population bias for turning left during spermatophore transfer. This is the first demonstration of asymmetrical sexual behaviour in an amphibian population. An experiment with a perfect female model showed that it was due to male rather than female lateralization. L eft turning bias decreased progressively as more spermatophores were deposited, and no significant bias was detectable by the third deposition. The hypothesis that this was due to neuromuscular fatigue was tested but not supported. Turning orientation had no influence on the probability of the female picking up the spermatophore in her cloaca. The left turning bias has not been found in the great crested newt, $T$. cristatus.
\end{abstract}

(C) 1997 The Association for the Study of A nimal Behaviour

Brain lateralization can lead to lateral asymmetries in the way that animals use their bodies during behaviour, both at the level of the individual and of the population (Bradshaw \& Rogers 1993). This phenomenon was once thought to be restricted to humans, but is now known to be widespread amongst mammals and birds (Bradshaw \& Rogers 1993; Rogers \& Workman 1993; Ward \& Hopkins 1993; Waters \& D enenberg 1994).

There is now growing evidence for the early evolution of brain lateralization and for widespread behavioural asymmetries in lower vertebrates (Bisazza et al. 1996a). European toads, Bufo bufo, show preferential use of their right forelimbs at the population level for removing objects placed on their heads, whilst South A merican cane toads, Bufo marinus, pivot in an asymmetrical way when turned upside down under water (Bisazza et al. 1996a). L ateral asymmetries have now been recorded in teleost fish at both the population and individual levels in the direction of turning during escape behaviour and during swimming in circular tanks (Cantalupo et al. 1995; Bisazza \& Vallortigara 1996; Bisazza et al. 1996b). Individual asymmetries have also been observed during lateral aggressive and court-

Correspondence: A. J. Green, Estación Biológica de D oñana, Consejo Superior de Investigaciones Cientificas, A partado 1056, 41080 Sevilla, Spain (email: andy@ebd03.ebd.csic.es). ship displays in Siamese fighting-fish, Betta splendens (C antalupo et al. 1996).

I am unaware of any previous studies of laterality in urodelan amphibians. Here I consider whether the smooth newt, Triturus vulgaris, a urodelan, shows lateral asymmetry during mating. Insemination is achieved in the Triturus newts when, following courtship, the female crawls parallel to and behind the male and touches his tail with her snout. The male then deposits a spermatophore and turns through 90 degrees so forming a barrier ahead of, and perpendicular to, the female, with his tail folded along the flank facing her. This male turning behaviour is known as 'creep-on' whilst the perpendicular position is known as 'brake' (Halliday 1974, 1975). The female crawls further until the male blocks her path, and at this point the female may pick up the spermatophore in her cloaca. This whole process may be repeated several times, with bouts of courtship display in between (H alliday 1974, 1975).

Here I investigate the turning orientation during creep-on of individual male smooth newts to assess the evidence for asymmetry at the population and individual levels. I present experiments that test the influence of female behaviour on male laterality, and the importance of short-term exhaustion in explaining an observed reduction in lateral bias over repeated spermatophore depositions. It has been suggested that population biases in lateralization may have an important 
Table I. Preferences for turning left or right at the population level in the triad and straitjacket experiments, analysed with sign tests

\begin{tabular}{|c|c|c|c|c|c|}
\hline & \multirow[b]{2}{*}{$\mathrm{N}$} & \multicolumn{2}{|c|}{$\begin{array}{c}\text { No. of males } \\
\text { showing preference }\end{array}$} & \multirow[b]{2}{*}{ z } & \multirow[b]{2}{*}{$\mathrm{P}$} \\
\hline & & L eft & R ight & & \\
\hline Triad & 37 & 26 & 7 & 3.13 & $<0.002$ \\
\hline Straitjacket & 74 & 49 & 17 & 3.82 & $<0.001$ \\
\hline
\end{tabular}

$\mathrm{N}$ is the number of males that deposited spermatophores. $\mathrm{z}$ is calculated via the normal approximation to the binomial distribution (Siegel $\&$ Castellan 1988).

influence on social interactions (Rogers 1989; Bisazza et al. 1996b). In this light, I also study the influence of turning orientation on the male's mating success (i.e. on the chances that his spermatophore is picked up by the female).

\section{METHO D S}

I conducted observations from $28 \mathrm{M}$ arch to 3 J une 1987. Smooth newts were collected from seven Oxfordshire ponds. $M$ ales and females were housed in separate aquaria on a natural light schedule, as described by Green (1991a). I used newts in two experiments and then returned them to the wild within a few days of collection. In the first experiment, which I call the 'triad experiment', I recorded courtship behaviour observed between groups of two males and a female for 30 min per group as described by Green (1991a). $U \mathrm{p}$ to three triads were observed each day. A total of 61 triads were observed, and each individual was used only once.

The second experiment, called the 'straitjacket experiment', was devised to test the influence of female behaviour and male fatigue on male be haviour using a perfect female model which I could manipulate. I anaesthetized females in a solution of m-aminobenzoate under a Home $O$ ffice licence, rinsed them in stock tank water and placed them in a 'straitjacket' (H alliday 1975). This consisted of split polythene tubing placed around the newt between the limbs and attached to a rigid Perspex rod. Females were kept anaesthetized in the jacket for up to $90 \mathrm{~min}$. I used the female to approach each male individually in order to elicit courtship. The male was then subjected to a courtship test similar to that used by H alliday (1976). I randomly assigned males to one of two treatment groups. In group 1, the female was made to elicit courtship by standing in front of the male for $1 \mathrm{~min}$ and was then made to approach the male continuously, thus eliciting spermatophore deposition, until he was unwilling to deposit any more spermatophores. In group 2, courtship was elicited in the same way, but I removed the female immediately after the male began to deposit his first spermatophore. A fter a 5-min interval, courtship was then continued as in group 1 until the male deposited all his spermatophores. M ales act on a limited supply of oxygen during courtship because they are unable to breathe at the water surface (Halliday \& Sweatman 1976; Halliday 1977). Hence a 5-min break is likely to relieve short-term neuromuscular fatigue.

The straitjacket experiment was conducted daily after the triad expriment. Some individuals were used in both experiments, although with a break of at least $30 \mathrm{~min}$ in between. One anaesthetized female was used each day. All females recovered completely within a few hours of the experiment. In both experiments, I noted the direction of turning in creep-on each time a male deposited a spermatophore.

\section{RESULTS}

$M$ ale newts showed a marked bias towards turning left after spermatophore deposition at the population level, during both the triad and straitjacket experiments (Table I). In the triad experiment, $70 \%$ of males turned more times to the left, $19 \%$ to the right and $11 \%$ had no bias. In the straitjacket experiment, $66 \%$ of males turned more times to the left, $23 \%$ to the right and $11 \%$ had no bias (Table I).

To consider the differences between individuals, and to assess the evidence for the existence of both 


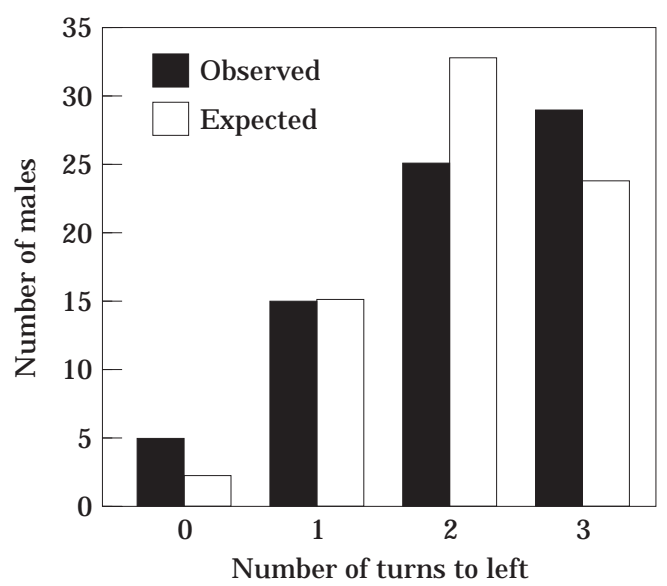

Figure 1. The number of turns to the left observed in the first three turns recorded for 74 males, compared with the numbers expected from the binomial distribution.

'left-turning' and 'right-turning' individuals in the population, I considered the first three depositions for the 73 males that deposited at least three spermatophores (pooling observations for the triad and straitjacket experiments). In total I recorded 152 left turns and 70 right turns. I compared the observed distribution between individuals with that expected if all individuals were equally biased towards the left (i.e. if all followed the same rule of turning left with $P=0.685$ and right with $P=0.315)$. The difference between the observed distribution and that expected from the binomial distribution was not statistically significant (F ig. $1 ; \chi_{3}^{2}=6.12$, Ns). SimiIar results were found when I analysed the first two depositions per male ( $N=84, \chi_{2}^{2}=0.87, \mathrm{NS}$ ) and the first four depositions per male $(\mathrm{N}=40$, $\left.\chi_{4}^{2}=8.88, \mathrm{Ns}\right)$.

Whilst the results of the triad and straitjacket experiments were very similar (Table I), for those 25 males who deposited spermatophores in both experiments, the bias towards turning left was stronger in the former than in the latter. For each of these males, I compared the orientation of the first $\mathrm{N}$ turns for each experiment, where $\mathrm{N}$ was the lowest number of depositions in either experiment (e.g. for a male turning left twice $(L L)$ in the triad experiment and $L R L$ in the straitjacket experiment, I compared $L L$ with $L R$ ). The number of left turns was higher in the triad experiment for 13 males, and lower for three males (sign test: $P<0.03)$.

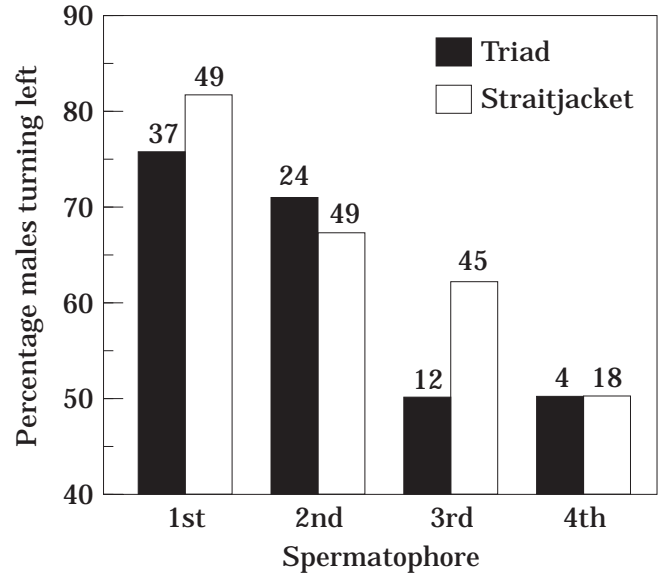

Figure 2. The percentage of turns to the left for the first four turns in the triad experiment and straitjacket experiment (excluding males that had already turned in the triad experiment). Numbers above the bars give the sample sizes. The combined bias towards the left is significant for the first two turns (sign tests: $P<0.01$ ), but not for the third and fourth.

Since all 25 individuals were subjected to the straitjacket experiment after the triad experiment, this result is explained by a weaker bias towards turning left as a male deposited more spermatophores (Fig. 2). For each male that turned both to the left and right (pooling males from the triad experiment with those in the straitjacket experiment not used in the triad experiment), I subtracted the median position of left turns from the median position of right turns (e.g. $L L R=1.5$, $L R L=0, R L L=-1.5$ ). There was a statistically significant tendency for these values to be above zero (W ilcoxon signed-ranks test: $W=148, N=43$, $\mathrm{N}$ for test $=34, \mathrm{P}<0.05$ ), that is the probability of turning to the right was higher in later depositions.

If the methodology of the straitjacket experiment genuinely reduced left turning bias, males depositing spermatophores in the triad experiment would show a stronger left bias than those depositing only in the straitjacket experiment. However, the opposite trend was recorded (Fig. 2). Whereas in the triad experiment only $76 \%$ of first brakes were to the left, in the straitjacket experiment $82 \%$ of first brakes were to the left $\left(\chi_{1}^{2}=0.45, \mathrm{Ns}\right)$.

The presence or absence of a 5-min break between the first and second depositions in the 
straitjacket experiment had no detectable influence on the change in left turning bias over successive depositions. Whereas in group 1 ( $N=33), 64 \%$ of males turned left after the second deposition, in group $2(\mathrm{~N}=38), 63 \%$ of second turns were to the left $\left(\chi_{1}^{2}=0.002\right.$, ns). Similarly, there was no difference between groups in the proportion of males switching orientation between the first and second depositions $\left(\chi_{2}^{2}=0.56, \mathrm{Ns}\right)$.

In the triad experiment, I considered whether the direction of turning had any influence on the probability that the female would pick up the male's spermatophore ('pick-up success'). Thirteen males turned both to the left and right whilst courting the same female. Pick-up success was higher for left turns in four males, and lower in six males (sign test: Ns).

\section{DISCUSSION}

$M$ ale smooth newts show a marked bias at the population level for left turning during spermatophore transfer behaviour. Very similar results were obtained both when mating was observed in seminatural conditions in the triad experiment and when anaesthetized females were manipulated to imitate responsive females in the straitjacket experiment. This suggests that the turning asymmetry is a consequence of male lateralization rather than a response to asymmetrical sensory input from females. The evidence from this study suggests that all male newts in the population may have the same left turning bias (Fig. 1). H owever, the presence of a right turning minority cannot be ruled out.

This is the first report of lateral asymmetry during sexual behaviour in amphibians. Asymmetrical sexual behaviour has only previously been described at the population level in birds. $M$ ale zebra finches, Taeniopygia guttata, tend to make courtship approaches with their right flank towards the female (Workman \& A ndrew 1991). Chickens, Gallus gallus domesticus, treated with testosterone show elevated sexual behaviour when tested monocularly with the right eye occluded, but not with the left eye occluded (Rogers et al. 1985). Individual male Siamese fighting-fish consistently present the same side of the body to females during courtship displays, although there is no laterality at the population level (Cantalupo et al. 1996). Individual male platyfish Xiphophorus (Platypoecilus) maculatus have also been reported to show lateral bias when thrusting their gonopodium towards females and during copulations (A ronson \& Clark 1952; Bisazza et al. 1996b). M orphological asymmetries at the population level lead to asymmetries in sexual behaviour in numerous invertebrate species, as in courtship in the fiddler crab U ca vocans (Davis 1978).

Whilst there is no known asymmetry in the external morphology of Triturus newts, an anatomical difference between the right and left habenular nuclei of the brain has been shown in T.cristatus (Braitenberg \& Kemali 1970). These nuclei may play a role in reproduction (Braitenberg \& K emali 1970), and they are also asymmetrical in Rana frogs, which have larger nuclei during the breeding season ( $\mathrm{K}$ emali et al. 1990). Thus this brain asymmetry in Triturus could be connected with the observed laterality in $T$. vulgaris sexual behaviour. It is also conceivable that lateralization in spermatophore transfer is related to asymmetry in abdominal organs, since this may make the abdominal twist required in brake easier to accommodate along one side (see D avis 1978; N aitoh \& W assersug 1996). H owever, this is difficult to reconcile with the reduced lateralization in later spermatophore depositions observed in the present study.

It has been suggested that brain lateralization may have evolved in aquatic ancestors of tetrapods to prevent conflicting responses elicited by stimuli perceived simultaneously from two laterally placed (largely monocular) eyes (A ndrew et al. 1982; Bradshaw \& R ogers 1993; Bisazza et al. 1996b; Cantalupo et al. 1996), such as those possessed by Triturus newts. F urther research is required to establish whether the asymmetrical turning recorded here in smooth newts is caused by visual lateralization. H owever, this behaviour may be guided by internal programming and perhaps tactile stimuli (from the substrate) more than by visual control. M ales make no response to female movements during creep-on (H alliday 1975). When males were given a break after the first deposition during my straitjacket experiment, females were removed before the male started to turn, and this had no apparent influence on entry into creep-on and brake behaviour, or on their orientation. F urthermore, male newts frequently turn into objects (e.g. aquarium walls) that block their path during creep-on (personal observation). 
This turning asymmetry in smooth newts may be connected with the laterality of limb use observed in other vertebrates, since opposing limbs are inevitably used differently when turning. However, it has often been proposed that limb laterality occurs only when limbs are used for manipulative activities such as feeding or handling objects (Walker 1980; Güntürkun et al. 1988). $M$ ale newts do not use their limbs for manipulating objects. Others have suggested that limb lateralization is a manifestation of lateralized cognitive visual processes (D avies \& G reen 1991; R ogers \& Workman 1993).

Turning asymmetry in smooth newts may reflect lateralized tail use rather than limb use. $M$ ale Triturus hold their tails to the side of the body throughout courtship and, after depositing a spermatophore, they simultaneously turn their body and fold their tails along the inner flank (H alliday 1974, 1975). In the related red-spotted newt, $N$ otophthalmus viridescens, the male moves his tail to one side into a position perpendicular to his body, predetermining the orientation of brake, before he deposits a spermatophore and begins to turn his body in creep-on (Verrell 1982).

These findings, and the recent demonstration of turning asymmetries in fish (C antalupo et al. 1995; Bisazza \& Vallortigara 1996; Bisazza et al. 1996b; Cantalupo et al. 1996), suggest that lateralized tail use predates the evolution of limbs and it may be widespread in vertebrates.

Courtship in urodelan amphibians is varied, with plenty of potential for asymmetric use of tails and asymmetric turns in species both with and without amplexus (A rnold 1977). The left turning bias recorded here in smooth newts does not seem to be shared by all members of the Triturus genus. I studied courtship in great crested newts $T$. cristatus (G reen 1989, 1991b) and recorded the orientation of each of six males in spermatophore transfer behaviour. Five males turned more to the right and one more to the left. Although this sample size is too small to confirm a right turning bias at the population level in this species (sign test: Ns), these data reveal a significant difference in orientation between great crested newts and the left turning smooth newts (comparing the orientation of the first turn observed for each male, using data from the triad experiment for smooth newts, Fisher's exact test: $P<0.01)$. G reat crested and smooth newts are not closely related and appear to have diverged in the M iocene (H alliday \& A rano 1991).
One plausible mechanism for the reduction in left turning bias in later depositions observed in smooth newts is neuromuscular fatigue. $M$ ales are limited by oxygen supply during courtship (H alliday \& Sweatman 1976; H alliday 1977) and, in brake, males push against females with their folded tail (H alliday 1974, 1975), requiring asymmetric muscular exertion. Furthermore, males conduct bouts of intense tail displays between each spermatophore deposition (Halliday 1974, 1975). Increasing fatigue may thus motivate a change in the orientation of brake after later depositions in the same way that a right-handed human carrying a heavy bag will at first use the right hand and then later begin to alternate. However, insertion of a 5-min break between depositions had no influence on subsequent turning orientation, and thus the reduction in bias over depositions appears not to be connected with short-term fatigue. $\mathrm{H}$ owever, it is conceivable that the accumulation of lactate during courtship requires longer than $5 \mathrm{~min}$ for recovery (see Bennett \& Licht 1974; Green 1991b). Alternatively, the reduction in lateralized turning over depositions may be linked to the general reduction in motivation for courtship observed as males deposit more spermatophores (Halliday 1976).

A lthough it has been suggested that the direction of lateralization may be important in social interactions (Rogers 1989; Bisazza et al. 1996b), there is no evidence for this in the present study. $M$ ale orientation during brake did not influence the probability of the female picking up the spermatophore in her cloaca, although the sample size was small. A high proportion of the variation in pick-up success between males has already been explained by variation in male crest height, female body size and recent female experience ( $G$ reen 1991a). If brake orientation influenced pick-up success there would be very strong selection for males to turn to the more successful side and thus the turning asymmetry would probably be much stronger than that observed.

\section{ACKNOWLEDGMENTS}

This work was funded by a Christopher Welch scholarship held at the Animal Behaviour Research Group, Department of Zoology, U niversity of Oxford and by a postdoctoral grant 
under the 'E stancias Temporales de Científicos y Tecnólogos Extranjeros en España' programme of the Spanish M inistry of Education and Science. I thank John Baker, Tim Halliday, Juan José Negro, Giorgio Vallortigara, Paul Verrell, Verina Waights and two anonymous referees for their helpful comments on early versions of the manuscript.

\section{REFERENCES}

A ndrew, R. J ., M ench, J . \& R ainey, C. 1982. R ight-left asymmetry of response to visual stimuli in the domestic chick. In: A nalysis of $V$ isual B ehaviour ( $E d$. by D.J. Ingle, M. A. Goodale \& R. J. M ansfield), pp. 197209. Cambridge, $M$ assachusetts: M IT Press.

A rnold, S. J. 1977. The evolution of courtship behavior in new world salamanders with some comments on old world salamanders. In: The Reproductive Biology of A mphibians (Ed. by D. H. Taylor \& S. I. G uttman), pp. 141-183. N ew Y ork: Plenum Press.

A ronson, L. R . \& Clark, E. 1952. Evidences of ambidexterity and laterality in the sexual behaviour of certain poeciliid fish. Am. $\mathrm{N}$ at., 828, 1601-1611.

Bennett, A. F . \& Licht, P. 1974. A naerobic metabolism during activity in amphibians. Comp. Biochem. Physiol., 48A, 319-327.

Bisazza, A. \& Vallortigara, G. 1996. R otational bias in mosquitofish (Gambusia holbrooki): the role of laterality and sun-compass navigation. L aterality, 1, 161175.

Bisazza, A ., Cantalupo, C., R obins, A ., R ogers, L. J . \& Vallortigara, G. 1996a. Right-pawedness in toads. N ature, L ond., 379, 408.

Bisazza, A., Cantalupo, C. \& Vallortigara, G. 1996b. $L$ ateralization of functions in the brain and behaviour of lower vertebrates: new evidences. Atti M emorie A ccadem. patavina, CVIII, 93-138.

Bradshaw, J. L. \& Rogers, L. J. 1993. The Evolution of $L$ ateral A symmetries, L anguage, Tool U se, and Intellect. San D iego: A cademic Press.

Braitenberg, V. \& K emali, M. 1970. Exceptions to bilateral symmetry in the epithalmus of lower vertebrates. J . comp. N eurol., 138, 137-146.

Cantalupo, C., Bisazza, A. \& Vallortigara, G. 1995. $L$ ateralization of predator-evasion response in a teleost fish (Girardinus falcatus). Neuropsychologia, 33, 1637-1646.

Cantalupo, C., Bisazza, A. \& Vallortigara, G. 1996. $L$ ateralization of displays during aggressive and courtship behaviour in the Siamese fighting-fish (B etta splendens). P hysiol. B ehav., 60, 249-252.

Davies, M. N . O. \& G reen, P. R. 1991. F ootedness in pigeons, or simply sleight of foot? A nim. Behav., 42, 311-312.

D avis, T . A . 1978. R eversible and irreversible lateralities in some animals. B ehav. Brain Sci., 2, 291-293.

Green, A. J. 1989. The sexual behaviour of the great crested newt, Triturus cristatus (A mphibia: Salamandridae). E thology, 83, 129-153.
G reen, A . J . 1991a. L arge male crests in the smooth newt, Triturus vulgaris (Salamandridae), an honest indicator of condition, are preferred by females at the spermatophore transfer stage. A nim. Behav., 41, 367-369.

Green, A. J. 1991b. Competition and energetic constraints in the courting great-crested newt, Triturus cristatus (A mphibia: Salamandridae). E thology, 87, 66-78.

G üntürkün, O., K esch, S. \& D elius, J. D. 1988. A bsence of footedness in domestic pigeons. A nim. Behav., 36, 602-623.

Halliday, T. R. 1974. Sexual behaviour of the smooth newt, Triturus vulgaris (U rodela: Salamandridae). J. H erpetol., 8, 277-292.

H alliday, T. R. 1975. A n observational and experimental study of sexual behaviour of the smooth newt, Triturus vulgaris (A mphibia: Salamandridae). A nim. Behav., 23, 291-322.

H alliday, T. R. 1976. The libidinous newt. A $n$ analysis of variations in the sexual behaviour of the male smooth newt, Triturus vulgaris (A mphibia: Salamandridae). A nim. Behav., 24, 398-414.

H alliday, T. R . 1977. The effect of experimental manipulation of breathing behaviour on the sexual behaviour of the smooth newt, Triturus vulgaris. A nim. Behav., 25, 39-45.

Halliday, T. R . \& A rano, B. 1991. Resolving the phylogeny of the European newts. Trends Ecol. Evol., 6, 113-117.

H alliday, T. R . \& Sweatman, H. P. A. 1976. To breathe or not to breathe; the newt's problem. A nim. B ehav., 24, 551-561.

K emali, M., Guglielmotti, V. \& Fiorino, L. 1990. The asymmetry of the habenular nuclei of female and male frogs in spring and winter. Brain Res., 517, 251-255.

Naitoh, T. \& W assersug, R. 1996. Why are toads right-handed? N ature, L ond., 380, 30-31.

Rogers, L. J. 1989. Laterality in animals. Int. J. comp. Psychol., 3, 5-25.

R ogers, L. J . \& W orkman, L. 1993. F ootedness in birds. A nim. B ehav., 45, 409-411.

Rogers, L. J., Zappia, J. V. \& Bullock, S. P. 1985. Testosterone and eye-brain asymmetry for copulation in chickens. Experientia, 41, 1447-1449.

Siegel, S. \& Castellan, N. J . 1988. N onparametric Statistics for the Behavioral Sciences. N ew Y ork: M cG rawHill.

Verrell, P. 1982. The sexual behaviour of the red-spotted newt, $N$ otophthalmus viridescens (A mphibia: urodela: salamandridae). A nim. B ehav., 30, 1224-1236.

Walker, S. F. 1980. Lateralization of functions in the vertebrate brain: a review. Br. J. Psychol., 671, 329367.

Ward, J. P. \& Hopkins, W. D. (Eds) 1993. Primate $L$ aterality: Current Behavioural Evidence of Primate A symmetries. N ew Y ork: Springer.

W aters, N. S. \& D enenberg, V. H. 1994. A nalysis of two measures of paw preference in a large population of inbred mice. Behav. Brain R es., 63, 195-204.

Workman, L. \& A ndrew, R. 1991. Population lateralization in zebra finch courtship: an unresolved issue. A nim. B ehav., 41, 545-546. 